\title{
A quantitative histopathological study of right bundle branch block complicating acute anteroseptal myocardial infarction
}

Masanori Okabe, Keisuke Fukuda, Yoshiyuki Nakashima, Tadayuki Hiroki, Kikuo Arakawa, Masahiro Kikuchi

\begin{abstract}
The aim of the present study was to evaluate whether necrosis of the right bundle branch is responsible for development of right bundle branch block in acute myocardial infarction. Twenty patients with acute anteroseptal myocardial infarction were studied-10 with right bundle branch block (group A) and 10 without (group B)-to evaluate by serial sectioning the pathological extent of myocardial infarction surrounding the right bundle branch and also that of right bundle branch necrosis. Myocardial infarction reached the right bundle branch more than $8 \mathrm{~mm}$ above the moderator band in all of group $A$, whereas myocardial infarction reached the right bundle branch less than $3 \mathrm{~mm}$ above the moderator band in only three patients in group B. Nine hearts in group A showed significant necrosis of the right bundle branch. In group $B$ and in one case with transient right bundle branch block no necrosis was found. The occurrence of right bundle branch block was almost entirely explained by necrosis of the right bundle branch, but transient right bundle branch block did develop without necrosis of the right bundle branch.
\end{abstract}

Though the outcome in patients with the complication of right bundle branch block in acute anteroseptal myocardial infarction is poor, ${ }^{1-3}$ there are few necropsy studies of the atrioventricular conduction system. Some workers concluded that reversible damage or functional impairment of the conducting cells or both have a major role in the development of conduction disturbances, ${ }^{45}$ whereas others encountered massive necrosis of the bundle branches. ${ }^{6-8}$

We examined the hypothesis that necrosis of the right bundle branch is a determinant of the occurrence of right bundle branch block in acute anteroseptal infarction. We measured the pathological extent of myocardial infarction surrounding the right bundle branch and necrosis of the right bundle branch in hearts from patients in whom right bundle branch block had developed during the course of acute anteroseptal infarction and in patients in whom it had not.

\section{Patients and methods}

We studied the morphology of the conduction system in ten hearts from patients who developed right bundle branch block during the course of acute anteroseptal infarction (group A) and compared the changes with those present in ten hearts from patients who died from acute anteroseptal infarction uncomplicated by right bundle branch block. We excluded patients who died within a day of the onset of myocardial infarction to ensure that the pathological analysis of myocardial infarction would be reliable. Acute anteroseptal infarction was diagnosed clinically and confirmed pathologically in both groups. The electrocardiographic criteria for right bundle branch block were a QRS interval that was longer than $0.12 \mathrm{~s}$ with a $\mathrm{QR}$ configuration in $\mathrm{V} 1$ and a slurred $\mathrm{S}$ wave in V6. ${ }^{910}$

The hearts were examined after fixation in $10 \%$ buffered formalin. Stenotic lesions of the epicardial coronary arteries were estimated by taking sections every $3 \mathrm{~mm}$, and stenosis of $\geqslant 75 \%$ of the vessel lumen was regarded as significant. Most of the upper (basal) interventricular septum was cut off in blocks approximately $3.5 \mathrm{~cm}$ wide and $3.0 \mathrm{~cm}$ long according to Lev's method. ${ }^{11}$ These blocks contained the atrioventricular conduction system, consisting of the atrioventricular node, the bundle of His, and the left and right bundle branches. These blocks were embedded in paraffin and sectioned $(6 \mu \mathrm{m})$ serially. We retained every twentieth section and stained it with haematoxylin-eosin, Masson's trichrome stain, and immunohistological stains for myoglobin.

On these sections we histologically determined the extent of the myocardial infarction surrounding the right bundle branch and studied the atrioventricular conduction system. After we had reconstructed the conduction system we subdivided the right bundle branch into three portions. ${ }^{112}$ The first portion is usually immediately beneath the endocardium, but occasionally deeper in the myocardium, and extends from the bundle branch bifurcation to the septomarginal trabeculum. The second portion consists of an intramyocardial segment in the septomarginal trabeculum. The third portion is subendocardial and runs from the lower border of the septomarginal trabeculum to the base of the anterolateral papillary muscle via the moderator band. We regarded the right 
Clinical details of the study groups

\begin{tabular}{|c|c|c|c|c|c|}
\hline Case & Age & $\operatorname{Sex}$ & From $M I$ to death & From $M I$ to $C R B B B$ & Cause of death \\
\hline \multicolumn{6}{|l|}{ Group A: } \\
\hline $\begin{array}{l}1^{\star} \\
2 \\
3 \\
4 \\
5 \\
6 \\
7 \\
8 \dagger \\
9 \\
10 \\
\text { Mean (SD) }\end{array}$ & $\begin{array}{l}63 \\
75 \\
64 \\
81 \\
71 \\
82 \\
84 \\
75 \\
64 \\
57 \\
71 \cdot 6(9 \cdot 3)\end{array}$ & $\begin{array}{l}M \\
M \\
M \\
M \\
F \\
M \\
M \\
M \\
F \\
M\end{array}$ & $\begin{array}{l}8 \text { day } \\
3 \text { day } \\
4 \text { day } \\
6 \text { day } \\
2 \text { day } \\
16 \text { day } \\
2 \text { day } \\
5 \text { day } \\
5 \text { day } \\
3 \text { day } \\
5 \cdot 4(4 \cdot 2)\end{array}$ & $\begin{array}{l}3 \text { day } \\
<14 \mathrm{~h} \\
2 \mathrm{~h} \\
<1 \mathrm{~h} \\
<14 \mathrm{~h} \\
<5 \text { day } \\
4 \mathrm{~h} \\
8 \mathrm{~h} \\
2 \text { day } \\
2 \text { day }\end{array}$ & $\begin{array}{l}\text { VT/Vf } \\
\text { Cardiogenic shock } \\
\text { Cardiogenic shock } \\
\text { Cardiogenic shock } \\
\text { Cardiogenic shock } \\
\text { Cardiogenic shock } \\
\text { Cardiogenic shock } \\
\text { VT/Vf } \\
\text { Cardiogenic shock } \\
\text { CHF }\end{array}$ \\
\hline \multicolumn{6}{|l|}{ Group B: } \\
\hline $\begin{array}{l}11 \\
12 \\
13 \\
14 \\
15 \\
16 \\
17 \\
18 \\
19 \\
20 \\
\text { Mean (SD) }\end{array}$ & $\begin{array}{l}77 \\
82 \\
68 \\
75 \\
81 \\
65 \\
47 \\
72 \\
55 \\
86 \\
70 \cdot 8(12 \cdot 4)\end{array}$ & $\begin{array}{l}\mathrm{M} \\
\mathrm{F} \\
\mathbf{M} \\
\mathbf{M} \\
\mathbf{M} \\
\mathbf{M} \\
\mathbf{M} \\
\mathbf{F} \\
\mathbf{M} \\
\mathbf{M}\end{array}$ & $\begin{array}{l}8 \text { day } \\
12 \text { day } \\
11 \text { day } \\
2 \text { day } \\
2 \text { day } \\
5 \text { day } \\
2 \text { day } \\
21 \text { day } \\
14 \text { day } \\
3 \text { day } \\
8 \cdot 0(6 \cdot 1)\end{array}$ & & $\begin{array}{l}\text { VT/Vf } \\
\text { VT/Vf } \\
\text { CHF } \\
\text { Cardiogenic shock } \\
\text { CHF } \\
\text { VT/Vf } \\
\text { Cardiogenic shock } \\
\text { Cardiogenic shock } \\
\text { VT/Vf } \\
\text { Cardiogenic shock }\end{array}$ \\
\hline
\end{tabular}

*A case of transient complete atrioventricular block.

tA case of transient CRBBB.

$\mathrm{CHF}$, congestive heart failure; CRBBB, complete right bundle branch block; MI, myocardial infarction; VT/Vf, ventricular tachycardia and/or fibrillation.

bundle branch as necrotic when we found coagulation necrosis of the conducting cells with or without evidence of healing, such as inflammatory cell infiltration and newly formed granulation tissue. ${ }^{13} \mathrm{We}$ based the estimate of the degree of right bundle branch necrosis on cross sectional area and classified it total (necrosis occupying $100 \%$ of the cross section of the right bundle branch), severe (75-90\%), moderate $(50-74 \%)$, and mild $(<50 \%)$.

\section{Results}

CLINICAL FINDINGS

The table shows the clinical summaries including the intervals between onset of myocardial infarction and the onset of right bundle branch block and death. Four patients in group $A$ had right bundle branch block on admission and in six it developed while they were in hospital. In all the patients except one (case 8), right bundle branch block was seen at the time of death. Right bundle branch block had been present for between one and 12 days. Patient 8 had transient right bundle branch block for 28 hours which developed eight hours after the onset of myocardial infarction. Patient 1 also had transient complete atrioventricular block.

\section{EXTENT OF INFARCTION SURROUNDING THE} RIGHT BUNDLE BRANCH

All cases showed significant stenoses of the left anterior descending coronary artery, with coronary thrombi in nine of group A and seven of group B. There was a significant lesion proximal to the origin of the first septal branch in nine group A hearts and five group B hearts. Single, double, and triple vessel disease was found in three, five, and two respectively in group A and two, three, and five in group B. Myocardial infarction was seen in the anteroseptal regions. Coagulation necrosis and some healing were identified histologically in all 20 hearts. Infarction adjacent to the right bundle branch was seen in all group $\mathrm{A}$ hearts, but in only three group B hearts, in which it was adjacent to the distal right bundle branch.

Figure 1 shows the anatomical relation between the extent of infarction and the right bundle branch. In all the group A hearts, the upper limit of infarction extended around the right bundle branch to more than $8 \mathrm{~mm}$ above the moderator band-that is to the proximal half of the second portion of the right bundle branch. In three group B hearts (cases 12, 15, and 16), infarction extended around the right bundle branch to less than $3 \mathrm{~mm}$ above the moderator band. In the remaining seven hearts, infarction did not reach the right bundle branch.

\section{NECROSIS OF THE RIGHT BUNDLE BRANCH}

Figure 2 shows the extent of right bundle branch necrosis. There was significant necrosis of the right bundle branch in nine of the group A hearts; this was total in three, severe in three, and moderate in three. There was no necrosis of the right bundle branch block in the remaining heart from the patient showing transient right bundle branch block (case 8 ) and the conducting cells were almost normal except for mild hydropic changes. There was no necrosis in any of the group B hearts, even in the three in which infarction was adjacent to the right bundle branch.

Figure 2 shows that infarction surrounding the right bundle branch did not coincide completely with right bundle branch necrosis. In five group A hearts (cases 3, 4, 5, 7, and 9) the most proximal involvement extended further than the necrosis of the right bundle branch. In the remaining four hearts (one in group $A$ and three in group B) we did not find necrosis of the right bundle branch despite infarction adjacent to the right bundle branch. In three of these (cases 12, 15, and 16), only a small distal portion of the right bundle branch was affected by infarction. In the remaining case (case 8 ) the 
Figure 1 Anatomical relation between margin of myocardial infarction and site of right bundle branch in cases with right bundle branch block and those without.

(A) Rectangular coordinates on the right ventricular surface of the interventricular septum that correspond to the boxed area in $(B)$. Coordinates intersect at the upper edge of cross section of the moderator band (arrow) where the third portion of the right bundle branch was

examined in each heart.

The shaded area shows

various courses of the right bundle branches in our cases. The margin of infarction closest to the base across the right bundle branch is shown for 13 hearts. In the remaining seven hearts without infarction adjacent to the right bundle branch, the highest point of infarction in the subendocardium of the right ventricular side of the interventricular septum is shown., group $A ; \bigcirc$, group $B .{ }^{\star} A$ case with transient right bundle branch block (heart 8). $R A$, right atrium; $R V$, right ventricle; $S T$, septomarginal trabeculum.

right bundle branch was not completely surrounded by infarcted myocardium.

Figure 3 shows that necrosis of the right bundle branch was more severe in the intramyocardial portion than in the subendocardial portion. The intramyocardial segment (that is, the second portion) almost always showed significant necrosis when it was surrounded by infarction, whereas the subendocardial segment (the third portion) rarely showed extensive necrosis. In hearts 3 and 9, however, necrosis of the third portion was unusually extensive. Mural thrombus covered the endocardial surface above the distal right bundle branch in heart 3 .

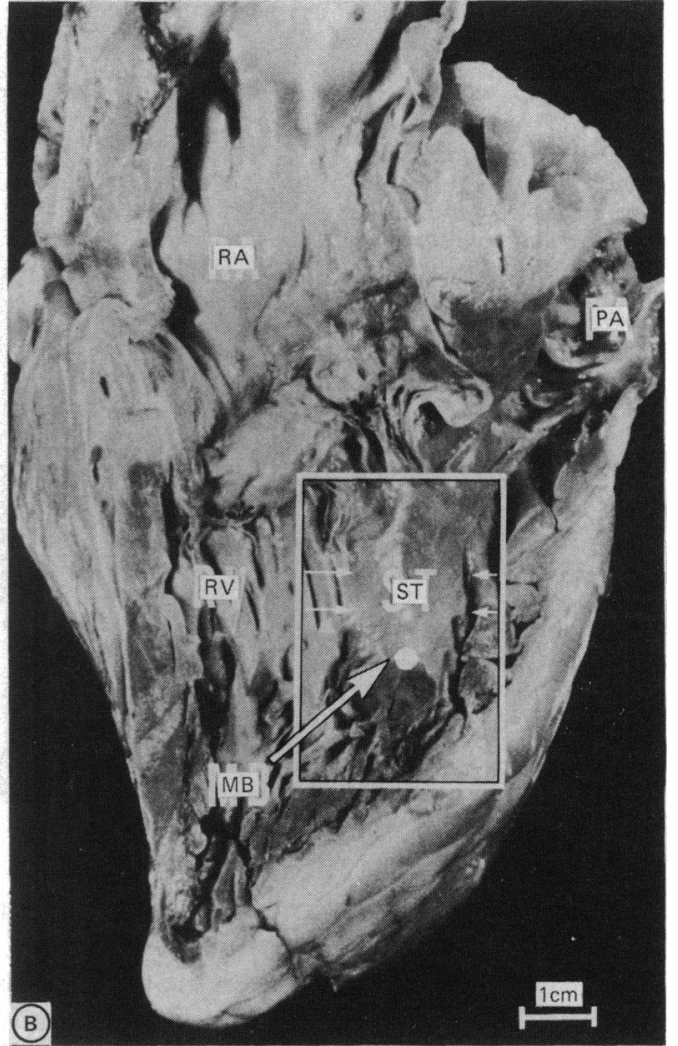

Discussion

Myocardial necrosis adjacent to the bundle branches was found in cases of acute anteroseptal myocardial infarction complicated by conduction disturbances. ${ }^{45}$ The extent of infarction surrounding the bundle branches, however, was not measured and the difference between the patients with bundle branch block and those without it has not been established. We found that in patients with acute anteroseptal infarction the margin of the necrosis adjacent to the right bundle branch was significantly closer to the base of the septum in those with right bundle branch block (group A) than in those without it (group B). There was

Figure 2

Semiquantitative presentation of necrosis of the right bundle branch in 13 hearts in which infarction reached the right bundle branch. The broken line across the right bundle branch represents the level of the most proximal front line of infarction in each heart. See fig 1 for other symbols.

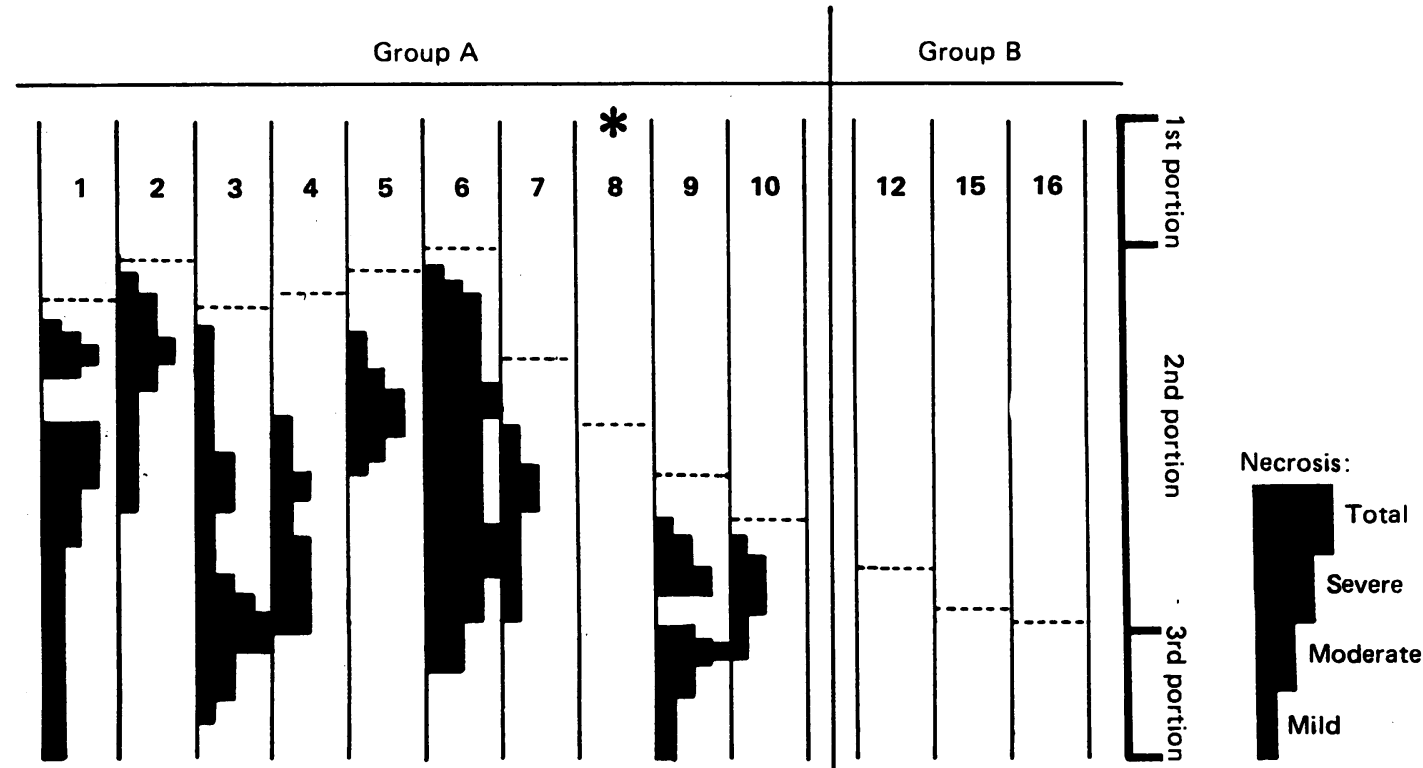


Figure 3 Histopathology of the right bundle branch (Masson's trichrome stain, original magnification $\times 50)$.

(A) $A$ massive infarction encroaches upon the second portion of the right bundle branch running in the intramyocardium, which shows significant necrosis (arrows). (B) Right bundle branch in the septomarginal trabeculum $5 \mathrm{~mm}$ distal from $(A)$ and unusually running in the subendocardium. It shows no necrosis despite the close proximity of infarction (arrows). (C) Third portion of the right bundle branch in the subendocardium showing no necrosis (arrow). All sections were obtained from heart 5 .

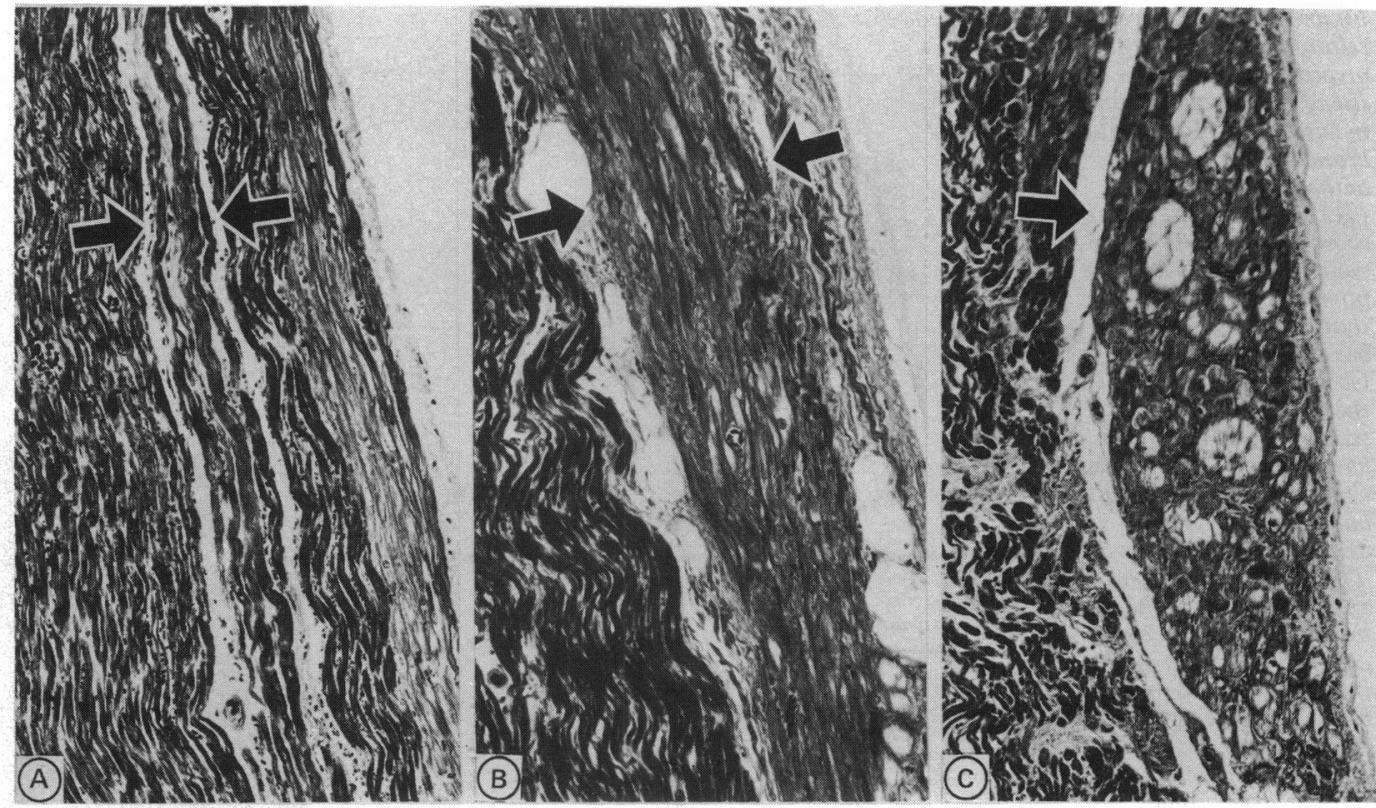

no overlap in the extent of the most proximal involvement of the right bundle branch between the two groups.

The present study focused on the complication of right bundle branch block because it can be accurately recognised on electrocardiography and because the morphological features of the right bundle branch simplify quantitative pathological analysis of features such as the degree of right bundle branch necrosis and the anatomical relation between the extent of infarction and the right bundle branch. The right bundle branch is a slender structure 1-2 mm in diameter that runs without branching through the interventricular septum until it reaches the anterolateral papillary muscle of the right ventricle. ${ }^{1114}$

The second main finding of the present study is the extremely good correlation between the degree of right bundle branch necrosis and the occurrence of right bundle branch block persisting until death. Though the severity of right bundle branch necrosis varied from mild to total, all the cases of persistent right bundle branch block showed significant (moderate or more severe) necrosis. $A \geqslant 50 \%$ decrease in number of the conducting cells on cross sections of the conduction system correlated well with chronic bundle branch or atrioventricular blocks. ${ }^{12}{ }^{15} \mathrm{We}$ found no necrosis in cases without right bundle branch block (group B).

We found extensive necrosis of the right bundle branch predominantly in the intramyocardial segment (the second portion) and rarely in the subendocardial segment (the third portion) (fig 2). This sparing of the subendocardium might be explained by retrograde perfusion through various left ventricular sinusoidal canals ${ }^{16}$ or through the left atrial venous system, ${ }^{17}$ or simply by direct diffusion of oxygen from the ventricular cavity through the endocardium.

Opinions vary about the histological lesions of the atrioventricular conduction system in acute anteroseptal infarction with bundle branch block. Some concluded that necrosis does not have a major role in the development of conduction disturbances. ${ }^{45}$ These complications have been attributed to reversible lesions, such as hydropic cell swelling, ${ }^{5}$ whereas others, like us, found that massive bundle branch necrosis was the lesion underlying conduction disturbances..$^{6-8}$

There are several explanations for these different findings about the pathological basis of conduction disturbances. One explanation is uncertainty about the duration of conduction disturbances. In acute myocardial infarction it is impossible to determine whether bundle branch block is transient or persistent, especially when the patient dies within a few days of the onset of infarction. This uncertainty about the duration of the block may influence the histological interpretation. Lie et al regarded right bundle branch block lasting more than six days as persistent. ${ }^{3}$ At least three cases (cases 1, 4, and 6) in our study fulfilled this criterion. Becker et al, however, reported that 18 of 22 patients died within four days of the onset of infarction in their series. This group emphasised reversible ischaemia as an underlying cause of right bundle branch block. ${ }^{5}$ Thus the observations of Becker et al may represent the pathogenesis of transient block whereas our findings may represent that of persistent block.

Differences in method are another explanation for the discrepancy. We used a serial sectioning technique and showed that there was discordance between the most proximal margin of infarction surrounding the right bundle branch and right bundle branch necrosis; this may arise because the conducting cells are more resistant to ischaemia than the contractile myocardial cells. ${ }^{1819}$ The study of Becker et al was based on an examination of several sections of tissue taken from parts containing the assumed course of the conduction system. ${ }^{5}$ This method is more likely to underestimate right bundle branch necrosis than serial and quantitative methods.

In the only case with transient right bundle branch block (case 8) that we studied the right 
bundle branch might have been less injured by ischaemia because the area of infarction surrounding the right bundle branch was not massive, even though it extended along the right bundle branch as far as it did in the cases with persistent right bundle branch block. We agree that degenerative changes or functional disorders of the conducting cells may be responsible for transient conduction disturbances. ${ }^{45}$ Hackel et al suggested non-serious and potentially reversible ischaemia of the conducting cells, the effect of potassium efflux from the infarcted myocardium surrounding the conduction system, or the effects of lytic enzymes released from infiltrating neutrophils as possible mechanisms. ${ }^{4}$

We conclude that right bundle branch necrosis of more than $50 \%$ of the cross sectional area is a major determinant for development of persistent right bundle branch block in acute anteroseptal infarction. Though there is a variable gap between the front line of myocardial infarction and that of right bundle branch necrosis, we found that infarction surrounding the right bundle branch more than $8 \mathrm{~mm}$ above the moderator band-that is, the proximal half of the second portion-was necessary before significant necrosis of the right bundle branch developed. Transient right bundle branch block, however, can develop when there is no necrosis of the right bundle branch.

We thank Miss M Kobayashi and Miss N Hirata for their technical assistance.

1 Norris RM, Mercer CJ, Croxson MS. Conduction disturbance due to anteroseptal myocardial infarction and their treatment by endocardial pacing. Am Heart $J$ 1972;84: treatme
2 Scheinman M, Brenman B. Clinical and anatomic implications of intraventricular conduction blocks in acute myocardial infarction. Circulation 1972;46:753-60

3 Lie KI, Wellens HJ, Schuilemburg RM, Becker AE, Durrer D. Factors influencing prognosis of bundle branch block complicating acute anteroseptal infarction. The value of His bundle recordings. Circulation 1974;50:935-41.

4 Hackel DB, Wanger G, Ratliff NB, Cies A, Estes EH Jr. Anatomic study of the cardiac conducting system in acute myocardial infarction. Am Heart $J$ 1972;83:77-81.

5 Becker AE, Lie KI, Anderson RH. Bundle-branch block in the setting of acute anteroseptal infarction. Clinicopathological correlation. Br Heart J 1978;40:773-82.

6 Blondeau $M$, Rizzon P, Lenegre $T$. Les trouble de la conduction auriculo-ventriculaire dans l'infarctus myocardique recent. Arch Mal Coeur 1961;54:1 104-17.

7 Sutton R, Davies MJ. The conduction system in acute Sutton $R$, Davies $M J$. The conduction system in acute
myocardial infarction complicated by heart block. Cirmyocardial infarction com
culation 1968;38:987-92.

8 Hunt D, Lie JT, Vohra J, Sloman G. Histopathology of heart block complicating acute myocardial infarction. Correlation with the His bundle electrogram. Circulation 1973;48:1252-61.

9 Horan LG, Flowers NC, Tolleson WJ, Thomas JR. The significance of diagnostic $Q$ waves in the presence of bundle branch block. Chest 1970;58:214-21.

10 Chou TC. Electrocardiography in clinical practice. 2nd ed. Orlando: Grune and Stratton, 1986:188-9.

11 Lev M, Windran J, Frickson E. A method for the histopathologic study of the atrioventricular node, bundle and branches. Arch Pathol 1951;52:73-83.

12 Fukuda K, Nakata Y, Okada R, Takagi T. Histopathological study on the conduction system of complete right bundle study on the conduction system of complete
branch block. Jpn Heart J1979;20:831-41.

13 Mallory GK, White PD, Salcedo-Salger J. The speed of healing of myocardial infarction. Am Heart J 1939;18: 647-71.

14 Davies MJ, Anderson RH, Becker AE. The conduction system of the heart. London: Butterworth, 1983:41.

15 Fukuda K. Histopathological study on the conduction system with complete atrioventricular block. With special reference to configuration of QRS complex. Jpn Circ J 1978;42:1265-78.

16 Myers WW, Hong CR. Amount and distribution of Rb86 transport into myocardium from ventricular lumen. $\mathrm{Am} \mathrm{J}$ Physiol 1966;211:739-45.

17 Moir TW. Study of luminal coronary collateral circulation in the beating canine heart. Circ Res 1969;24:735-44.

18 Bagdonas AA, Stucky JH, Piera J, Amer NS, Hoffman BF. Effects of ischemia and hypoxia on the specialized conduction system of the canine heart. Am Heart J 1961;61: 206-18.

19 Greenspan K, Cranefield PF. Influence of some factors on oxygen uptake of canine cardiac Purkinje fibers. Am Physiol 1963;204:5-8. 